\title{
FORTE REAL DO BOM JESUS - RESGATE DE UMA HISTÓRIA DE RESISTÊNCIA E ESQUECIMENTO- RECIFE, PE, BRASIL
}

\section{Ana Catarina Peregrino Torres Ramos*}

\section{André Luis Silva Feitosa **}

RESUMO: O Forte Real do Bom Jesus foi um importante exemplar do sistema defensivo da capitania de Pernambuco na luta contra a invasão dos holandeses. No século XIX a pesquisa para localizar o forte é retomada pelo Instituto Arqueológico, Histórico e Geográfico Pernambucano e sua localização é descoberta. As primeiras campanhas arqueológicas na busca das ruínas do forte só foram realizadas entre os anos de 1968 e 1969. Embora a pesquisa tenha sido bastante divulgada e seus resultados parciais veiculados nos jornais da época, as campanhas não geraram relatórios científicos, prática pouco comum nas pesquisas arqueológicas da época. Aqui se traz informações dessas campanhas realizadas pelo arqueólogo Marcos Albuquerque, que responde a alguns questionamentos com o propósito de se resgatar alguns detalhes dessas primeiras campanhas arqueológicas realizadas no Forte Real do Bom Jesus, que resultaram na sua evidenciação material e considerações iniciais.

Palavras-Chaves: Forte Real do Bom Jesus, escavações arqueológicas, material arqueológico

ABSTRACT: The Bom Jesus Fort was an important example of the defensive system of the captaincy of Pernambuco in the fight against the invasion of the Dutch. In century XIX the research to locate the fort is taken up by the Archaeological, Historical and Geographic Institute Pernambucano and its location is indicated. The first archaeological campaigns in search of the ruins of the fort were only carried out between the years of 1968 and 1969. Although the research was well publicized and its partial results published in the newspapers of the time, the campaigns did not generate scientific reports, practice not very common in the searches of the time. Here we bring information from these campaigns carried out by the archaeologist Marcos Albuquerque that answers some questions in the search to recover some details of these first archaeological campaigns carried out in the Bom Jesus Fort, which resulted in their material evidence and initial considerations.

**Discente do Programa de Pósgraduaçao em Arqueologia da Universidade Federal de Keywords: Real Fort of Bom Jesus, archaeological excavations, archaeological material 


\section{Introdução}

Na década de 1960 foram evidenciados arqueologicamente os remanescentes estruturais do ponto principal do sistema defensivo luso-brasileiro contra o avanço das tropas da Companhia das Índias Ocidentais ${ }^{1}$ : o Forte Real do Bom Jesus ou Arraial do Bom Jesus (Figura 01). Construído estrategicamente em posição equidistante da vila de Olinda e do porto do Recife, imediatamente após a invasão e tomada da capitania de Pernambuco pelos holandeses em 1630, constituiu-se como o foco central de uma série de unidades defensivas que visavam manter os holandeses restritos ao litoral, impedindo seu acesso à área produtora de açúcar. Além dos seus defensores, o forte agregou também um grande contingente de civis a procura de segurança, formando-se assim um povoado em suas imediações.

A fortificação teve um curto, porém conturbado, período de atuação. Rechaçou diversos ataques holandeses, além de fornecer tropas móveis para a guerrilha que impedia os invasores de conquistarem o interior da capitania. Relatos da época, dentre eles o do próprio comandante Arciszewisky, responsável pela sua conquista, dão conta de ter se tratado de um forte extremamente sólido.

Entretanto, em sua luta de resistência, a partir de 1633, os luso-brasileiros vão paulatinamente perdendo seus postos avançados, o que permite aos holandeses investirem de forma mais contundente contra o forte. Após um pesado assédio e prolongado cerco, o forte se encontrava praticamente arrasado e seus defensores exauridos, face à interrupção do abastecimento de água e víveres, vindo a capitular no ano de 1635.

Após cinco anos de resistência, o Forte Real do Bom Jesus é tomado, sendo arrasado e a posição abandonada abrindo caminho aos invasores. Por se tratar de um forte construído com terra, suas muralhas quando derrubadas, entulharam o fosso. Séculos de abandono, associados à ação de agentes naturais, encobriram todos os demais vestígios estruturais da antiga fortificação, que foi aos poucos desaparecendo também da memória coletiva. Quando da passagem do Imperador D.Pedro II, por Pernambuco, em meados do século XIX, este procurou visitar os remanescentes do forte. A partir de informações de que não existiam vestígios superficiais da antiga praça fortificada, o imperador lamentou a falta de interesse dos

\footnotetext{
1 Empresa de capital privado sediada em Amsterdã com objetivos diversos, dentre eles de enfraquecer as bases econômicas Ultramarinas da Coroa Ibérica, assim como controlar as atividades comerciais no Atlântico (Mello, 1978; Miranda, 2014).
} 
Pernambucanos sobre sua história, além de recomendar uma análise mais detalhada da área (D.Pedro II, 1952).

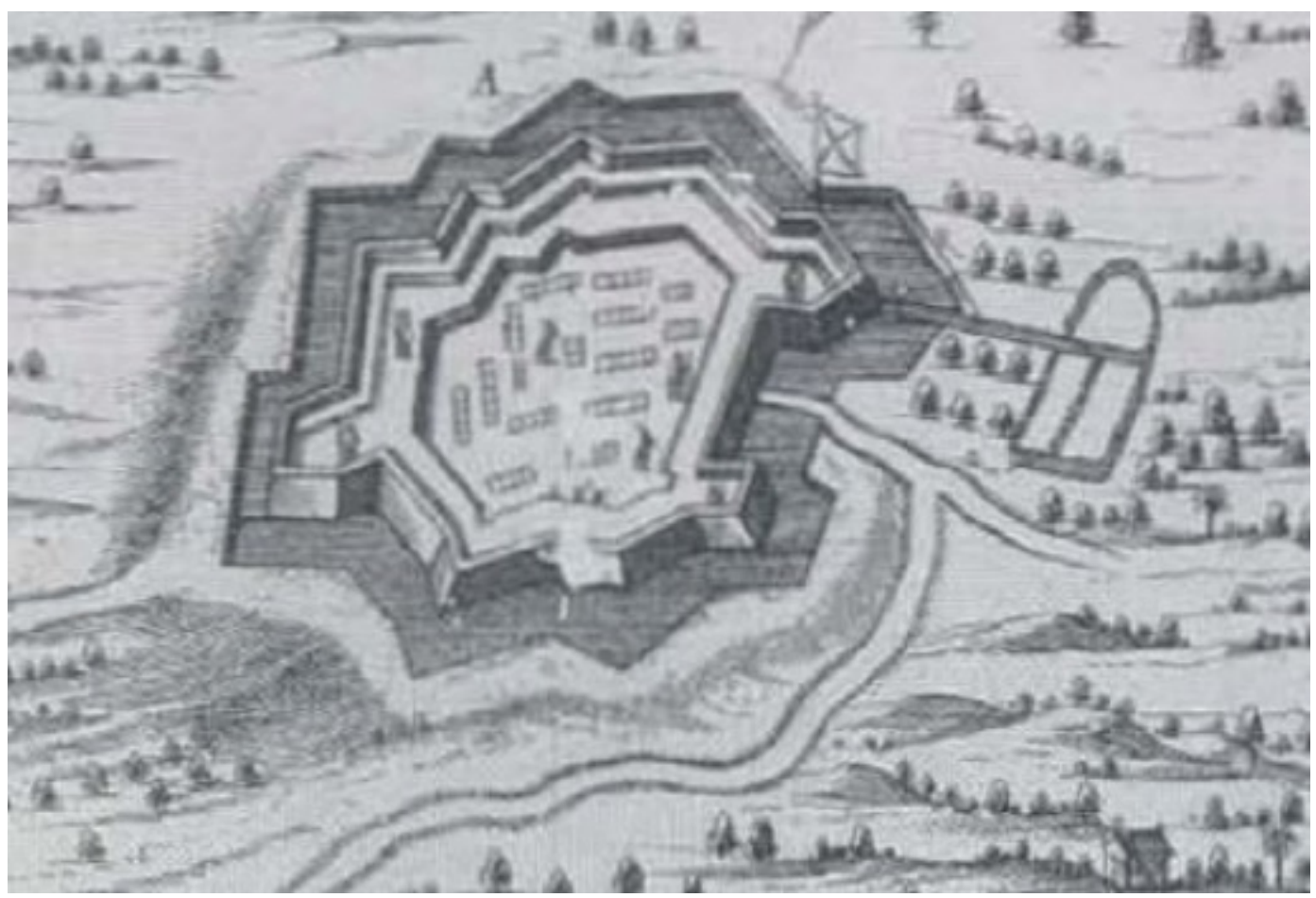

Figura 1: Pormenor da gravura "représente le fiege \& la prise dela puissante Forteresse de l'Arraal ou Royal dedans le Brief", representando a estrutura do Forte Real do Bom Jesus em 1635, presente na obra de Commelyn (1656).

Inserido dentro do atual Bairro de Casa Amarela, Zona Norte da cidade do Recife, o crescimento urbano tomou parte do território que pertenceu a antiga fortificação, ficando seus remanescentes restritos aos limites do Sítio da Trindade, antiga propriedade pertencente à família Trindade Perreti em fins do século XIX, transformado em Bem de Utilidade Pública em 1952. Hoje o Sítio da Trindade possui 6,5 hectares de área verde. Ele foi tombado pelo Iphan em 1974, classificada como conjunto paisagístico (Vainsencher, 2004).

Relevante iniciativa tomou também o Instituto Arqueológico, Histórico e Geográfico Pernambucano - IAHGP, Ainda No Século XIX, Quando Se Chegou Ao Local Aproximado Onde teria existido o antigo Arraial. Todavia, foi com a pesquisa arqueológica que a sua existência se materializou de fato. Trabalho coordenado pelo arqueólogo e professor Marcos Albuquerque, que trouxe importantes contribuições ao entendimento do período conhecido como "Guerra Holandesa".

As primeiras campanhas arqueológicas foram realizadas entre os anos de 1968 e 1969. Embora a pesquisa tenha sido bastante divulgada e seus resultados parciais veiculados nos jornais da 
época, as campanhas não geraram relatórios científicos, prática pouco comum nas pesquisas arqueológicas da época. Todavia, as duas campanhas posteriores em 1988 e em 2009 tiveram seus resultados publicados (Albuquerque e Lucena, 1988; Albuquerque; Lucena e Walmsley, 1999; Albuquerque; Lucena e Nogueira, 2009a; Albuquerque; Lucena e Nogueira, 2009b)².

O Prof. Marcos Albuquerque é um dos pioneiros da Arqueologia Histórica no Brasil, dedicandose ininterruptamente a pesquisa arqueológica há mais de cinquenta anos. O trabalho de Marcos Albuquerque desenvolve-se principalmente no âmbito da expansão do Sistema Cultural Europeu em terras americanas, com foco na pesquisa arqueológica de fortificações, campo do qual é uma das principais referências no Brasil.

Atuando desde a década de 1960 com a pesquisa arqueológica de campos de batalha e unidades fortificadas, Marcos Albuquerque tem trazido grandes contribuições ao conhecimento do Sistema Defensivo Brasileiro, não ficando restrito apenas ao estado de Pernambuco. Na região Norte do país escavou e/ou realizou reconhecimentos arqueológicos no Forte de Óbidos, no estado do Pará (Lucena, 1993), na colônia militar de D. Pedro II e no Forte Príncipe da Beira, ambos no estado do Amapá (Albuquerque, 2008). Em Pernambuco escavou e reconheceu unidades fortificadas como o Forte Orange, na Ilha de Itamaracá, em diversas campanhas; o Forte de Santo Inácio, em Tamandaré (reconhecimento na década de 1960); os Fortes do Brum e de Pau Amarelo; o campo de batalha do Monte das Tabocas, em Vitória de Santo Antão (Albuquerque; Lucena e Walmsley, 1999); o reduto do Tejucupapo (Albuquerque, op.cit); e o campo de Batalha dos Guararapes (Albuquerque, op.cit) ${ }^{3}$. Destacase também a pesquisa arqueológica realizada no Forte dos reis Magos, no Rio Grande do Norte (Albuquerque; Lucena e Maciel, 2014). Mais recentemente, Marcos Albuquerque e sua equipe escavou o Fortim da Ilha do Guedes, estrutura em terra inserida no contexto da tomada de Porto Calvo pelas tropas Holandesas, em Alagoas.

A presente entrevista busca resgatar detalhes das primeiras campanhas arqueológicas realizadas no Forte Real do Bom Jesus, que resultaram em sua evidenciação material e suas principais conclusões.

- Em se tratando da história do Forte Real do Bom Jesus, percebe-se um lapso temporal no que diz respeito aos dados históricos e documentais, referentes ao período anterior a

\footnotetext{
${ }^{2}$ Parte dos referidos trabalhos estão disponíveis no seguinte endereço eletrônico: http://brasilarqueologico.com.br/index.php 3 Idem.
} 
instalação do Forte e logo após a sua capitulação. Como se chegou a hipótese acerca da localização dos remanescentes do Forte Real do Bom Jesus? Foi utilizada apenas a aproximação conseguida pelo IAHGP ou partiu-se de outras fontes de dados? Como o local se encontrava antes das campanhas de 1968/1969?

Resposta: Com base nos dados disponíveis os pesquisadores do IAHGP, em um período áureo de sua existência, produziram muitas informações subsidiados em documentação primária e em vistorias de campo. Não apenas o Forte, como ainda outras localidades de interesse histórico. Deve-se muito a acuidade e afinco desses pesquisadores em uma fase anterior a internet e a equipamentos como o GPS.

Tomando como base inicial os dados produzidos pelos pesquisadores do IAHGP, foi realizada uma vistoria na área e concluiu-se ser no atual Sitio da Trindade, o local ideal para a instalação de uma fortificação com a finalidade a que se destinava. Era um outeiro natural que se destacava da topografia no seu entorno.

Em momento anterior a primeira campanha arqueológica, a topografia do terreno encontravase homogênea com uma declividade em direção a atual estrada do Arraial. Talvez a melhor forma de se descrever o estado topográfico anterior as escavações seja o de se imaginar a topografia atual com o fosso fechado, ou seja, um terreno sem vestígios superficiais indicativos de qualquer estrutura antrópica em seu interior.

Uma grande contribuição para o entendimento da guerra holandesa em Pernambuco foi a descoberta material dessa Unidade de Defesa que se tinha apenas informação documental. Outra contribuição, lamentavelmente ainda não aproveitada, poderia ser a sua inclusão para um roteiro turístico cultural voltado para a guerra holandesa no Brasil.

\section{- Quais eram as expectativas arqueológicas relativas ao conteúdo do sítio? Foram localizados} contextos estratigráficos íntegros?

Resposta: Com relação a expectativa arqueológica diria que foi uma atitude ousada, tanto para mim, em termos de experiência, como para o estágio em que se encontrava a Arqueologia Histórica no Brasil. Parti do pressuposto de que, se a estrutura fortificada tivesse um fosso, este, mesmo que entulhado, deixaria marcas de seu encaixe no conjunto sedimentar do Grupo Barreiras. Ao se realizar cortes no sentido da parte plana, que poderia ser a Praça D`Armas, em direção a Estrada do Arraial ter-se-ia, necessariamente, que passar por marcas da escarpa ou contra escarpa da fortificação. De fato, trabalhou-se bastante no terreno natural, sem 
nenhum vestígio de material arqueológico, até que se atingiu a área do fosso de textura e composição diferenciada, apresentando material arqueológico contemporâneo ao período em questão.

Ao ser removido o material de entulho, resultante do desmoronamento da muralha foram identificados vários ângulos salientes e reentrantes da fortificação. Ainda do ponto de vista estratigráfico foi identificado um paleosolo, pisoteado pelos ocupantes da fortificação e que se encontrava completamente soterrado (Figura 2).

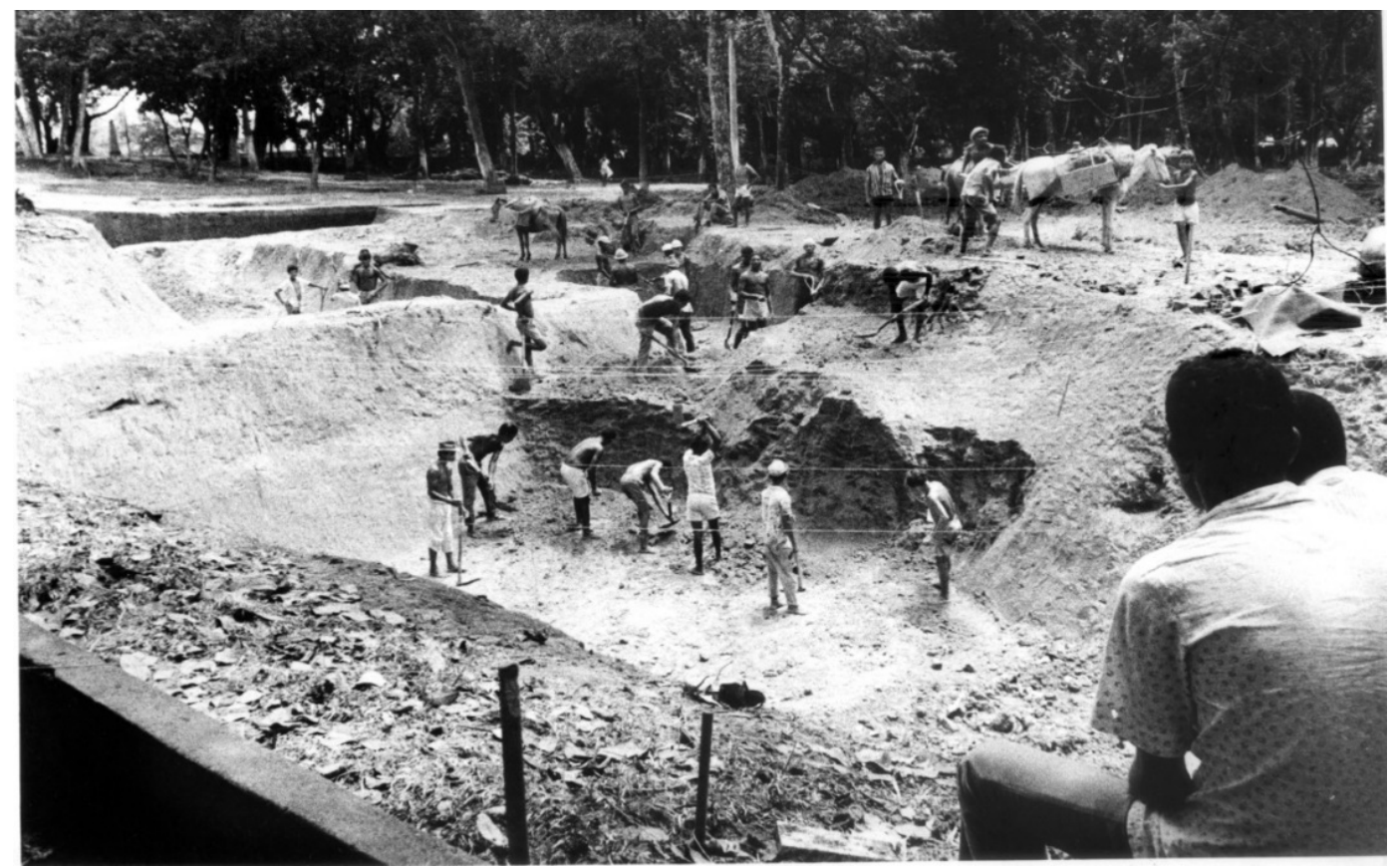

Figura 2: Trabalhos de desobstrução do entulho do fosso do Forte Real do Bom Jesus, conforme notícia veiculada em jornais da época. Fonte: Jornal Universitário - Recife-PE - Setembro, 1972.

- Quais foram os subsistemas relativos a fortificação que puderam ser evidenciados na campanha? Quais categorias de material arqueológico podem ser associadas a cada subsistema?

Resposta: O material arqueológico encontrado nas escavações pode ser associado a material bélico como espada, projéteis de mosquete e de canhão (figuras 3 e 4), inclusive um projetil de canhão disparado pelos holandeses em um reduto que se encontrava no morro da Conceição. Este projetil estava alojado na escarpa do fosso, o que permitiu recompor a sua trajetória. Além do material bélico foram encontrados restos alimentares como carapaças de ostra, ossos de mamíferos e louça de diferentes origens. 


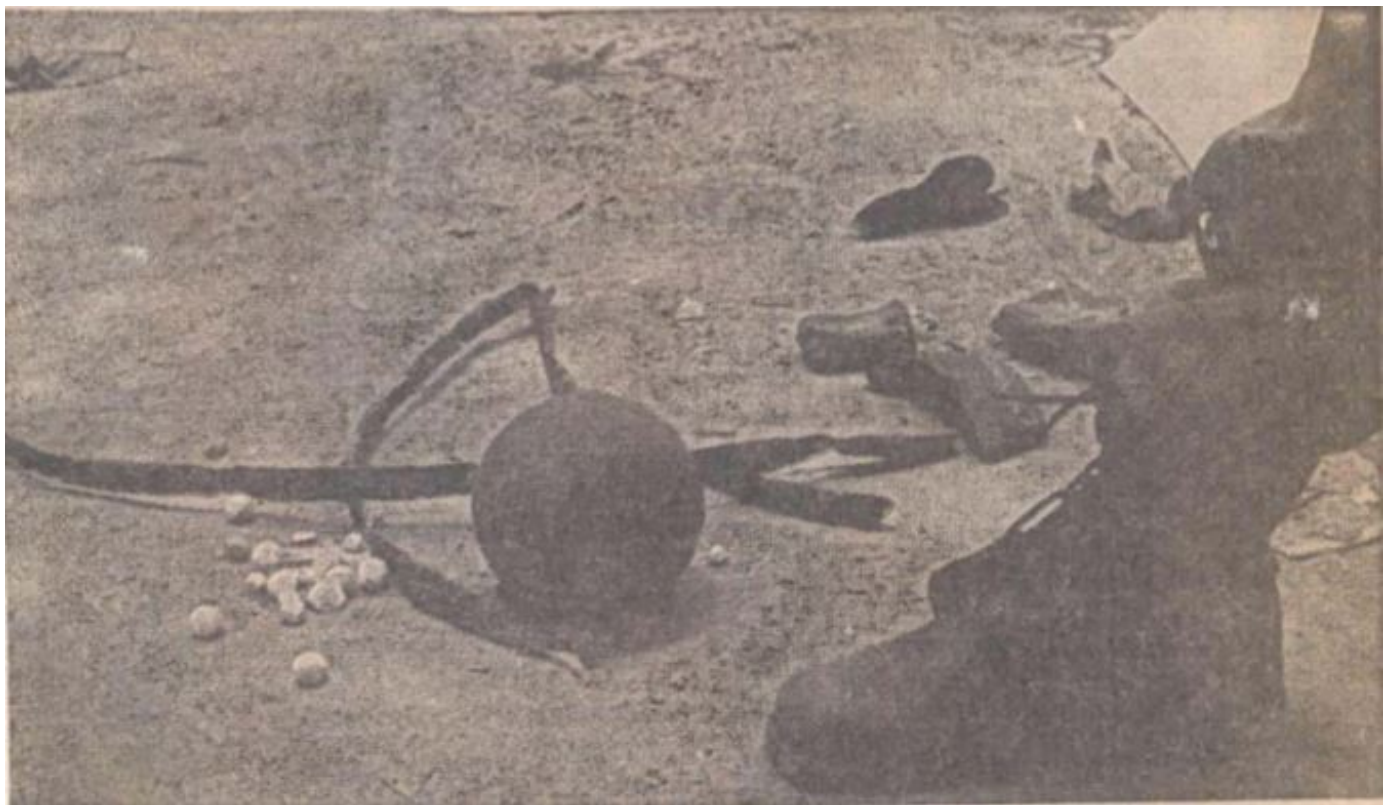

Figura 3: Material encontrado nas escavações do fosso do Forte Real do Bom Jesus. Fonte - Diario de Pernambuco, Recife-PE, 06.10.1968.

\section{- Fale-nos um pouco sobre os métodos e técnicas empregados nas etapas de pré-escavação e escavação?}

Resposta: Foi realizado na época da primeira campanha uma sequencia de cortes medindo $2 \mathrm{~m}$ $\mathrm{X} 2 \mathrm{~m}$. Esses cortes deixavam as 4 paredes laterais a mostra, de forma que se acompanhava as alterações da estratigrafia em todos os sentidos. Como os cortes eram sequenciais, se dispunha de uma visão de trincheira. No momento em que se percebeu uma inclinação no perfil compatível com a escarpa de um fosso, a escavação foi continuada com o objetivo de se encontrar a contra escarpa, que também foi encontrada. Após esta confirmação das duas extremidades do fosso, com composição e textura diferenciada, teve início a desobstrução do fosso, em cortes com níveis artificiais de $20 \mathrm{~cm}$. Com esta técnica de escavação, o trecho do fosso trabalhado ficou completamente a mostra (Figura 5). 


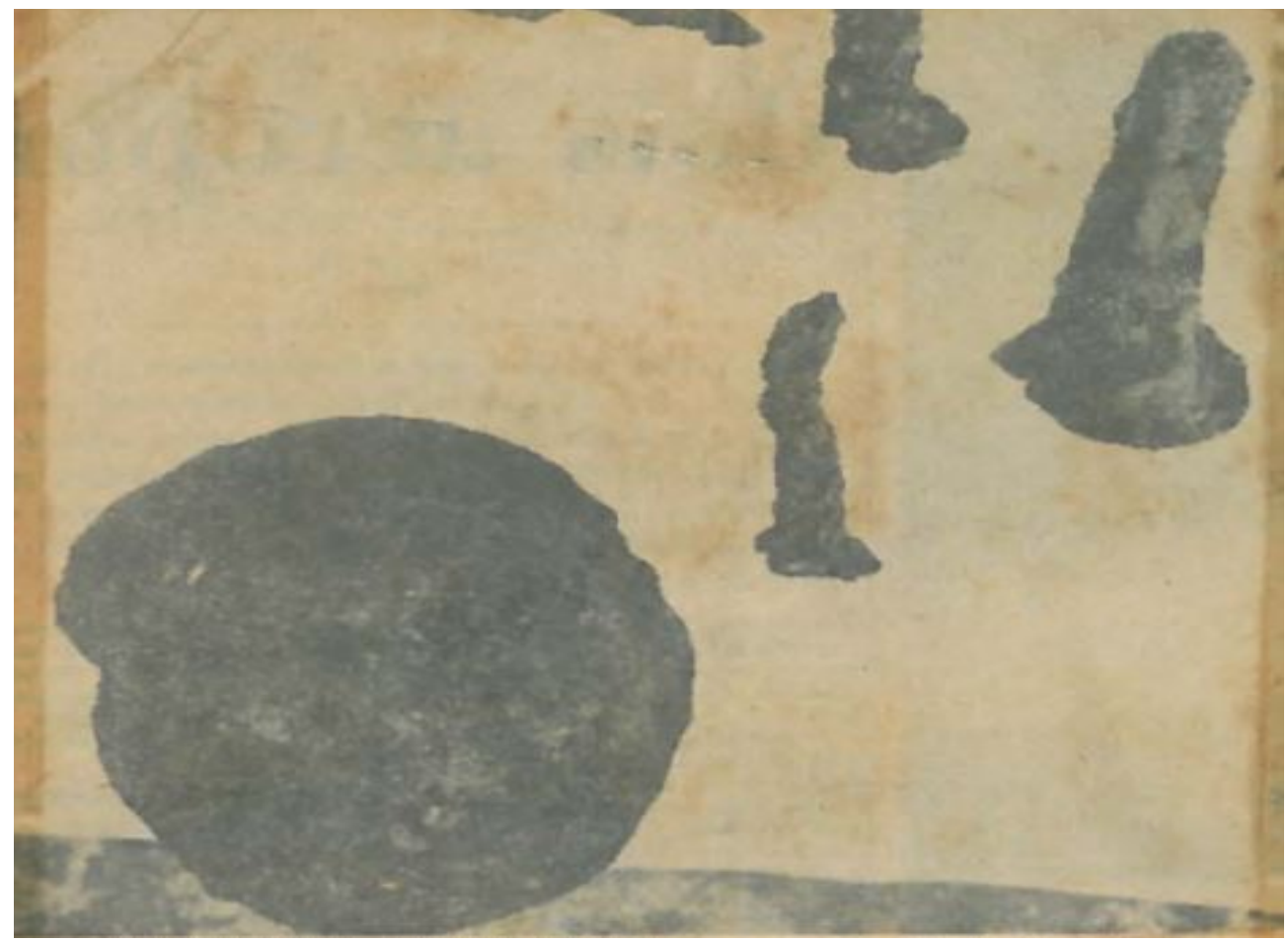

Figura 4: Materiais em ferro encontrado nas escavações. Fonte - Diario de Pernambuco, Recife-PE, 06.10.1968.

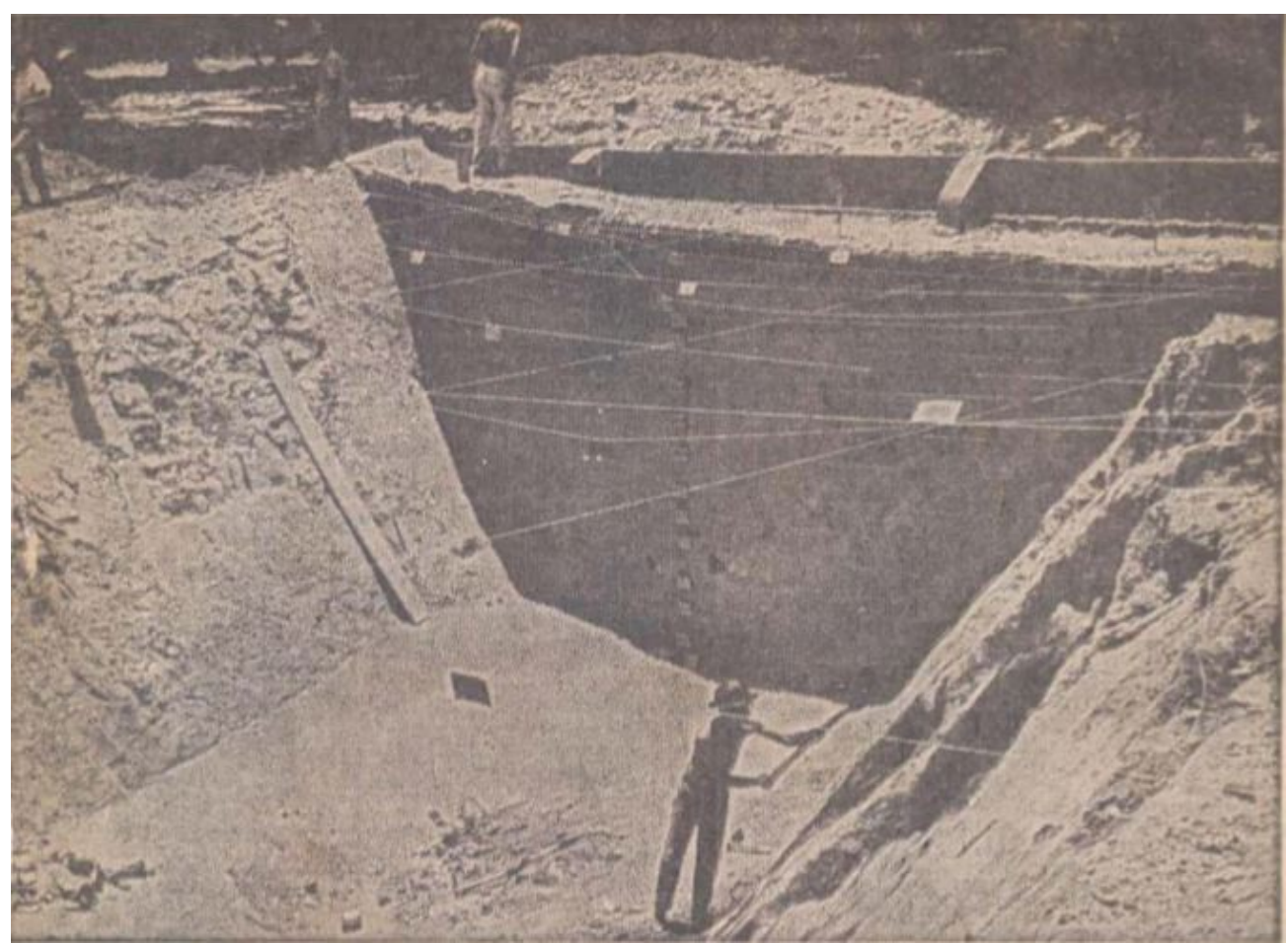

Figura 5: Trecho do fosso duplo evidenciado com a pesquisa arqueológica. Fonte: Albuquerque; Lucena e Walmsley, 1999. 
- Quais são as principais conclusões que as campanhas arqueológicas de 1968/1969 trouxeram para o entendimento da guerra holandesa em Pernambuco?

RESPOSTA: O resultado da pesquisa arqueológica permitiu a materialização de uma informação textual e iconográfica. Materialização que não apenas evidenciou parte da fortificação, como ainda permitiu o entendimento de suas dimensões. O material arqueológico encontrado no fosso trouxe significativas informações sobre o cotidiano de seus ocupantes. Outra informação significativa para o entendimento do cerco ao forte foi a presença de um projetil de canhão encontrado na escarpa do fosso que, quando recuperado a sua trajetória, pode confirmar uma informação iconográfica de uma posição holandesa no morro da Conceição (Figura 6).

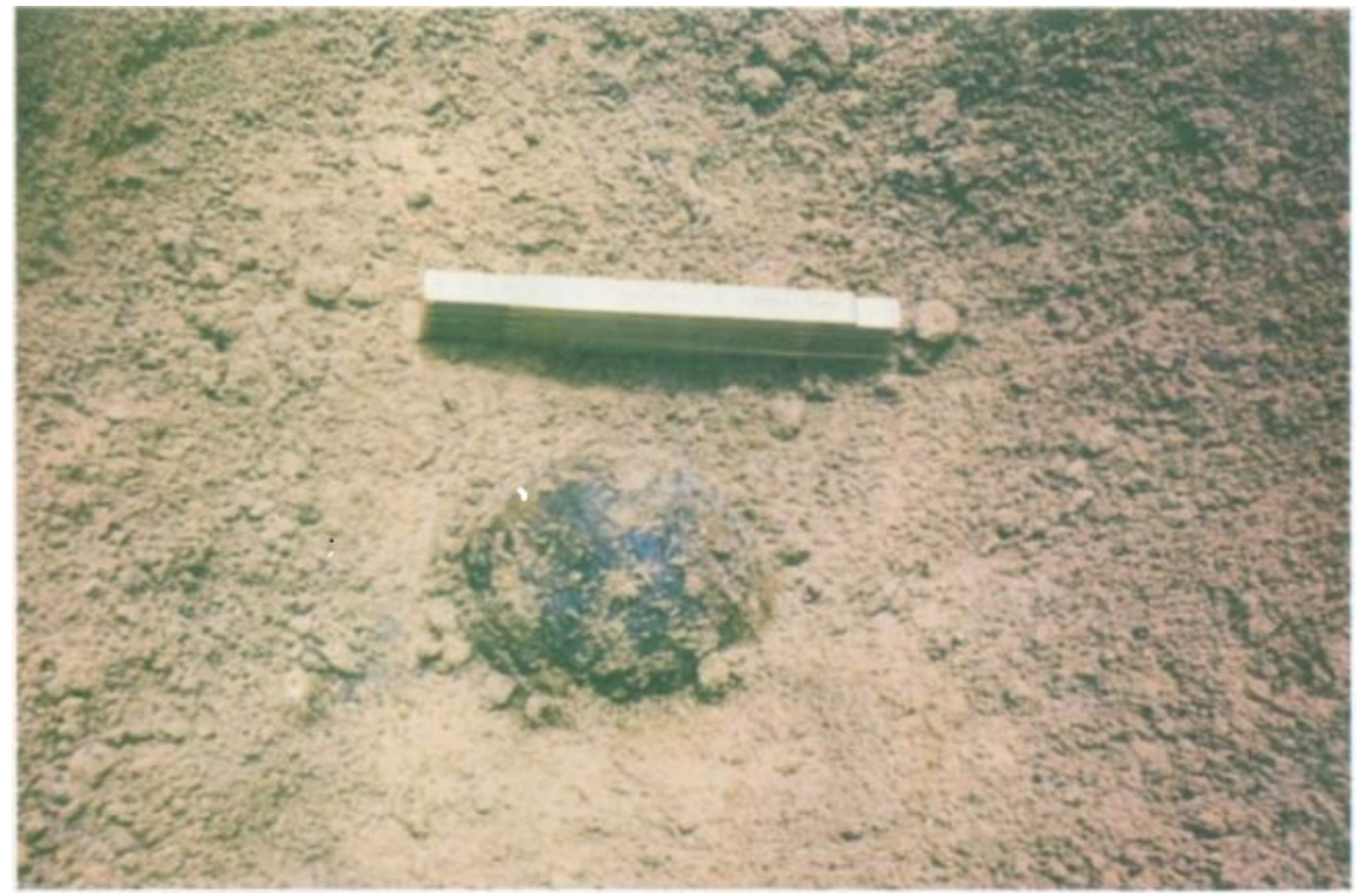

Figura 6: Projétil de canhão alojado na escarpa do Forte. Fonte: Albuquerque; Lucena e Walmsley, 1999.

- Além do conhecimento sobre os grupos humanos, a partir dos elementos materiais de sua cultura, entende-se que a Arqueologia tem uma grande importância social, principalmente no que diz respeito a formação educacional de um povo a respeito de seu patrimônio. Uma pesquisa do vulto que foi a evidenciação material dos remanescentes do Forte Real do Bom Jesus não evitou que o sítio passasse por momentos de total abandono ${ }^{4}$. Em sua opinião,

${ }^{4}$ Aproximadamente vinte anos após as primeiras campanhas arqueológicas realizadas na área, o trecho do fosso da fortificação encontrava-se novamente entulhado. Uma nova campanha foi realizada no ano de 1988, no intuito de desobstruir a área escavada 
qual deve ser a postura do pesquisador não apenas no retorno do conhecimento proveniente da Arqueologia à sociedade, mas também na prevenção e conservação dos sítios arqueológicos?

RESPOSTA: Acredito que alguns arqueólogos podem se dedicar a preservação e educação patrimonial de um determinado monumento. Entretanto, penso que a função primordial do arqueólogo é descobrir, evidenciar, participar ativamente do processo de restauração, sugerindo aspectos positivos e negativos da proposta de restauração, porém não é função do arqueólogo se responsabilizar por atividades que competem a outros profissionais. No caso particular dessa fortificação, a mesma encontra-se em área da municipalidade e é tombado pelo Iphan a nível federal. Penso que a responsabilidade da preservação do monumento cabe aos departamentos de cultura dos respectivos órgãos e a cobrança deverá ser realizada pela população a quem realmente o Bem pertence. Durante a etapa da pesquisa cabe ao arqueólogo responsável promover um trabalho de Educação Patrimonial. Em todos os nossos trabalhos, ao longo de décadas, sempre as escavações estiveram abertas ao público, acompanhados por um técnico qualificado. Frequentemente me encontro com pessoas que relembram o que viram nas escavações do Forte Real do Bom Jesus, o que é muito gratificante para o pesquisador.

\section{Referências}

ALBUQUERQUE, M. 2008. Arqueologia da Fortaleza de São José do Macapá. Revista da Cultura. Rio de janeiro, n.14, ano VIII, p. $41-46$, Jun

ALBUQUERQUE, M.; LUCENA, V. 1988. Forte Real do Bom Jesus: resgate arqueológico de um sítio histórico. Recife: CEPE.

ALUBUQUERQUE, M.; LUCENA, V.; WALMSLEY, D. 1999. Fortes de Pernambuco: imagens do presente e do passado. Recife: Graftorre.

ALBUQUerque, M.; LUCENA, V.; NOGUeIRA, R. 2009a Pesquisa arqueológica no Sítio Trindade - Casa Amarela, Recife - Pernambuco. Relatório Final, v. 1. Recife.

ALBUQUeRQUe, M.; LUCENA, V.; NOGUEIRA, R. 2009b. Pesquisa arqueológica no Sítio Trindade - Casa Amarela, Recife - Pernambuco. Relatório Final, v. 2. Recife.

e propor medidas de conservação do monumento (Albuquerque e Lucena, 1988). Ironicamente, após um novo período de aproximadamente vinte anos, o forte se encontrava novamente abandonado e tomado por vegetação de médio e grande porte. Em 2009 foi realizada uma nova campanha arqueológica a fim de recuperar o fosso e ampliar novas áreas de escavação (Albuquerque, Lucena e Nogueira, 2009). 
ALBUQUeRQUE, M.; LUCENA, V.; MACIEL, D. 2014. Programa de pesquisa arqueológica interventiva e de Educação Patrimonial no Forte dos Reis Magos, em Natal, Rio Grande do Norte. Relatório Final. Recife.

LUCENA, V. 1993. O forte de Óbidos, uma unidade de defesa na conquista do Norte do Brasil: um projeto de pesquisa. In: REUNIÃO CIENTÍFICA DA SOCIEDADE DE ARQUEOLOGIA BRASILEIRA - SAB 7., 1993, João Pessoa. Resumo. João Pessoa: SAB/CNPq. p. 114.

COMMELYN, I. 1656. Historie de La Vie \& Actesmemorables de Frederich Henry de Nassau, Prince d’Orange. Amsterdan.

D.Pedro II. 1952. Viagem a Pernambuco em 1859. Secretaria do Interior e Justiça. Recife: Arquivo Público Estadual.

MELLO, J. A. G. de. 1978. Tempo dos Flamengos: Influência da ocupação holandesa na vida e na cultura do Norte do Brasil. $2^{\circ}$ ed, vol. XV, Coleção Pernambucana. Recife: Governo do Estado de Pernambuco.

MIRANDA, B.R. F. 2014. Gente de Guerra: origem, cotidiano e resistência do exército da Companhia das Índias Ocidentais no Brasil (1630-1654). Recife: Editora UFPE.

VAINSENCHER, S. A. 2018. Sítio da Trindade (Recife, PE). Pesquisa Escolar Online, Fundação Joaquim Nabuco, Recife, 2004. Disponível em: <http://basilio.fundaj.gov.br/pesquisaescolar/index.php>. Acesso em: 07-12-2018.

Marcos procura fosso do velho Arraial. Jornal Universitário, Recife-PE. Setembro, 1972. Disponível em: http://www.brasilarqueologico.com.br/materias/1972/01.09.1972\%20-

\%20Jornal\%20Universit\%C3\%A1rio\%20\%20Marcos\%20procura\%20fosso\%20no\%20Velho\%20Arraial.pdf . Acesso em: 07-12-2018

Diario de Pernambuco, Recife-PE, 06.10.1968. 